\title{
Quantifing model uncertainity to improve stream flow prediction geba cathment, upper tekeze River basin, Ethiopia
}

\begin{abstract}
This study was conducted to predict stream flow at the outlet of the gauged Geba watershed and analyze the associated uncertainty that can affects its accurate prediction. Semi distributed HBV light model was applied to estimate stream flow of the Geba catchment and associated uncertainty through Monte Carlo Simulation procedure. The calibration and validation of the model was found satisfactory as performance rating criteria value of coefficient of correlation $\left(\mathrm{R}^{2}\right)$ and Nash-Sutcliffe simulation efficiency $\left(\mathrm{E}_{\mathrm{vS}}\right)$ is found to be 0.74 and 0.72 for calibration and 0.73 and 0.70 for validation ,respectively. In the same order from the model uncertainties analysis the percentage of the simulated data within the uncertainty bound is only $35 \%$ for calibration and $29 \%$ for validation, which shows that there is uncertainty in the process. Then using Monte Carlo Simulation procedure in HBV light model parameter uncertainty was tested and found with ENS value of 0.76 for calibration and 0.79 for validation. And this shows that the overall associated uncertainty come from either conceptual or input or a combination of them but not from parameter identification. Even though the predicted amount of flow of $955.33 \mathrm{MCM}$ is almost equivalent to the latest study, the uncertainty might come due to either neglected abstractions or poor quality of input data. Therefore, this simulated amount should not be used for any water resource development works unless the correction of these cause of uncertainties are reduced as uncertainty in estimation of simulated flow will lead to wrong water resource management decision.
\end{abstract}

Keywords: flow prediction, HBV light, ERDAS, model uncertainty, geba cathment
Volume 4 Issue I - 2020

\author{
Abebe Temesgen \\ Hydraulic and Water Resources Engineering Faculty, Arbaminch \\ Water Technology Institute, Ethiopia
}

\begin{abstract}
Correspondence: Abebe Temesgen, Hydraulic and Water Resources Engineering Faculty, Arbaminch Water Technology Institute,Arbaminch, Ethiopia, Email teabema@gmail.com
\end{abstract}

Received: December 10, 2019 | Published: January 09, 2020

\section{Introduction}

Developing the basic relationships between the different hydrologic systems like rainfall, runoff, soil moisture, ground water level and land use land cover are crucial for effective and sustainable water resources planning and management activities with the support of hydrological models. ${ }^{1}$ Models are generally used as utility or supporting tools in various areas of water resources development, in assessing the available water resources in different areas for studying the impacts of human interference in an area such as land use change, deforestation and other hydraulics structures such as dams and reservoirs. $^{2}$

Lack of data is one of the main limitations for hydrological modeling. However, it is often used as a justification for over simplifying, poorly performing models. ${ }^{3}$ If we want to enhance our understanding of hydrological systems, it is important to fully exploit the information contained in the available data, and to learn from model deficiencies. ${ }^{4}$ In order to model rainfall-runoff process, a variety of hydrological models have been applied. ${ }^{5}$ But the applications of models are different due to the fact that catchments are heterogeneous; In this regard HBV light is used for understanding hydrological processes better and prediction of environmental changes. Moreover, in data scarce region e.g.Tekeze basin and understanding of catchment behavior and impact assessment are crucial from the perspective of sustainable water resources development point of view. Thus, this research will be conducted in the Geba cathment of upper
Tekeze sub basin with the aim of predicting discharge in terms of model conceptualization, parameterization and capturing the response mode of the daily hydrographs during the wet and dry seasons.

\section{Materials and methods}

\section{Description of study area}

The Geba cathment drains the north-eastern part of the Tekeze River Basin and is located in northern Ethiopia, Tigray Regional State. This research focuses on the upper part of the watershed which covers about $2437.52 \mathrm{~km}^{2}$. The study area is bounded between latitudes $13^{\circ} 16^{\prime}$ and $14^{\circ} 16^{\prime}$ North and longitudes $38^{\circ} 38^{\prime}$ and $39^{\circ} 49^{\prime}$ East. There is a considerable variation in altitudes over the basin with a maximum altitude of $3298.45 \mathrm{~m}$ a.s.1., a minimum altitude of $1747.04 \mathrm{~m}$ a.s.l and an average altitude of $2000 \mathrm{~m}$ a.s. $1 .^{6}$ The topography of the basin is highly controlled by erosion features and geological structures. Sharp cliffs and steep slopes occurs along the major rivers (Figure 1). ${ }^{7}$

\section{Data collection}

The metrological and hydrological data required for this study were collected from Ethiopian national meterologiocal agency (NMA) and ministry of water irrigation and electricity (MoWIE). Metrological data from 1992-2012, flow data from 2002-2012 were collected and DEM (Digital elevation model of $30 * 30$ was collected from Ethiopian mapping agency. Soil map from MoWIE and ERDAS LULC 2008 classification was prepared for further investigation. 


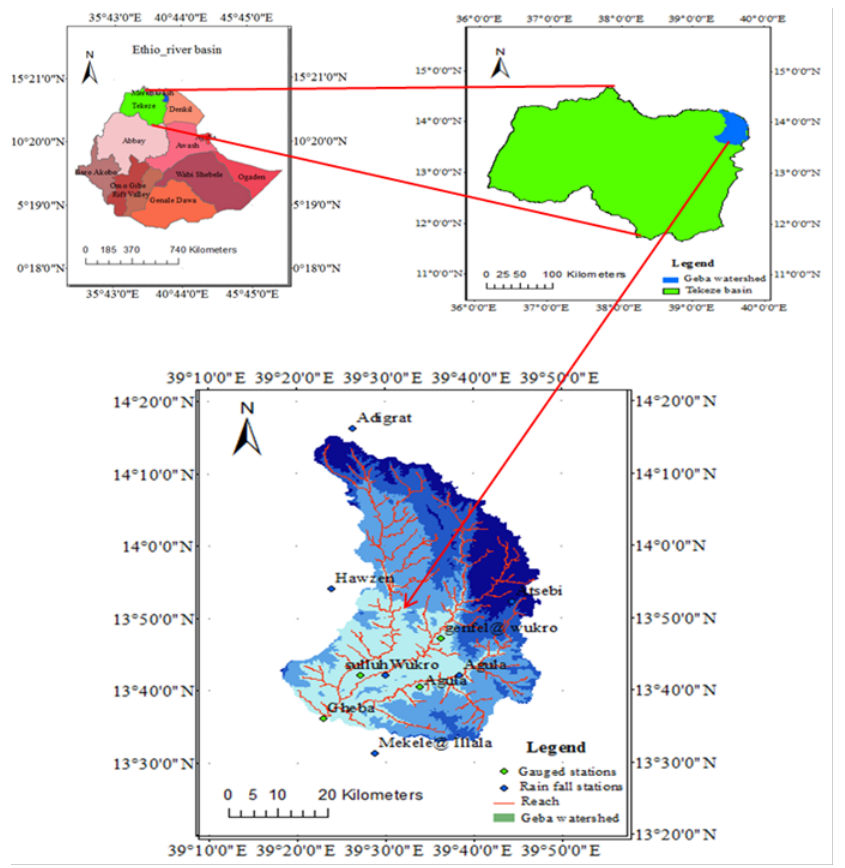

Figure I Location of the study area.

\section{Data analysis}

In this study station average and normal ratio method were used to complete missing data of all stations. Double mass curve was used to check the homogeneity and consistency of rainfall as well for adjustment of inconsistent data. The Penman-Monteith method is recommended as the sole method for determining reference evapotranspiration (ETo) when the standard meteorological variables including air temperature, relative humidity and sunshine hours data are available. ${ }^{8}$ However, those data are not available in all stations in this study area. So, Potential evapotranspiration was calculated by using Hargreaves method since most of the stations have maximum and minimum temperature in all stations.

Model sensitivity analysis: Sensitivity analysis was applied manually by changing the value of one model parameter at a time for SWAT model through SWAT CUP and Monte Carlo Simulation for HBV light model. That is the value of each model parameter was increased and decreased up to $60 \%$ by $20 \%$ interval and those having steep slopes are considered as most sensitive while those having moderate to gentle slopes are less sensitive.

\section{Model calibration}

It was performed manually by trial and error from 2002 to 2012 by changing one model parameter at a time until the model simulated stream flow match with observed stream flow.

Model performance: For this study the model performance was evaluated by $\mathrm{E}_{\mathrm{NS}}, \mathrm{R}^{2}$ and PBIAS for HBV light for the calibration and validation period.

Uncertainity analysis for both models: Due to errors in different condition either in input data, model performance or parameter selection the model commonly affected by uncertainity. For this study Monte carlo simulation procedure. ${ }^{9}$ was used for HBV light model.

\section{Spatial temporal data}

Topographic map: SRTM $30 \times 30$ DEM was downloaded from earth explorer. The Geba cathment was extracted from Rift valley basin DEM (Figure 2).

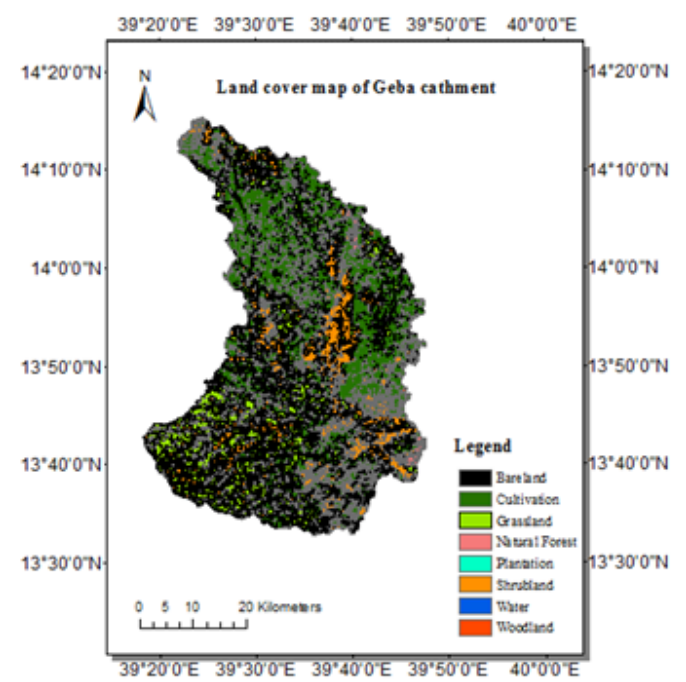

Figure 2 SRTM $30 * 30$ DEM of Geba watershed.

Landuse landcover map: From ERDAS 2008 LULC map for the study is the generated classification are as follows Shurbland, Cultivation, bareland, woodland, waterbody, plantation, natural forest and grass land (Figure 3).

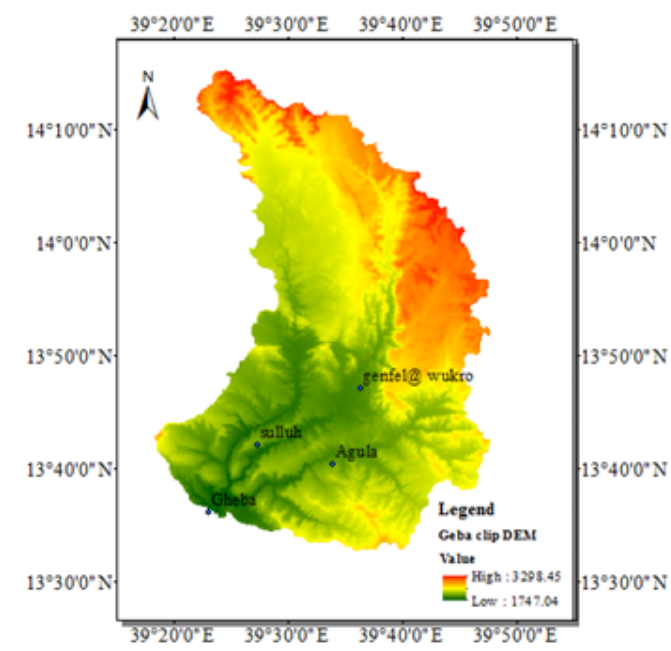

Figure 3 Land cover map of Geba watershed.

\section{Results and disscussions}

\section{Model Development HBV Light}

Sensitivity Analysis: For Geba cathment the most sensitive parameters are K2, MAXBAS and BETA where as the rest model parameters are less sensitive or insensitive through out the simulation period. And from the below the dominant process for the HBV light model is subsurface or ground water dominance since as compared to others its K2 (storage or recession coefficient at box 2) is sensitive through out the objective functions (Figures 4-6). 


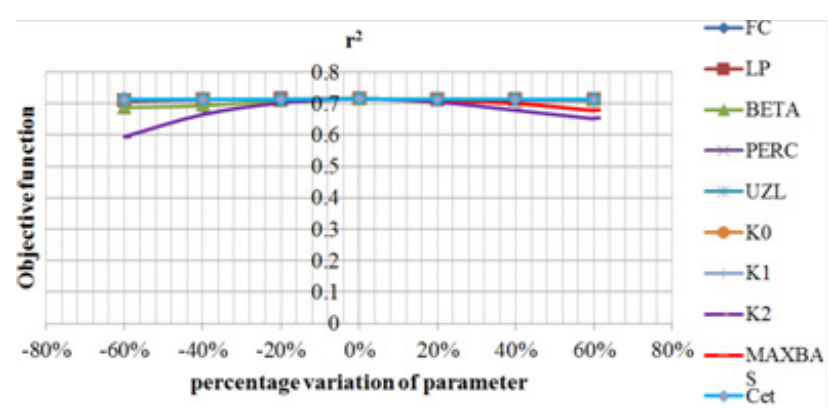

Figure 4 Sensitivity analysis by considering $r^{2}$.

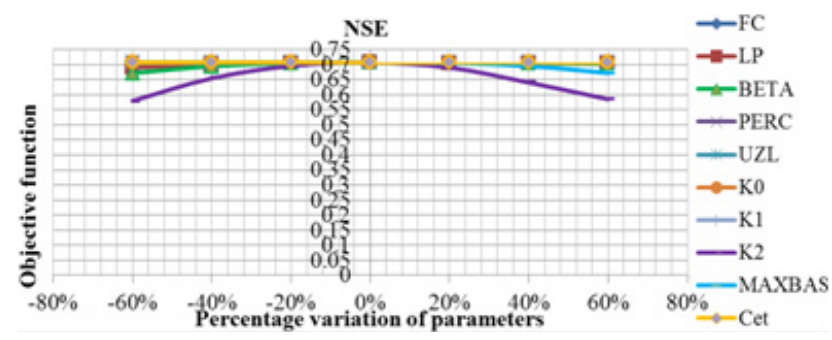

Figure 5 Sensitivity analysis by considering NSE.

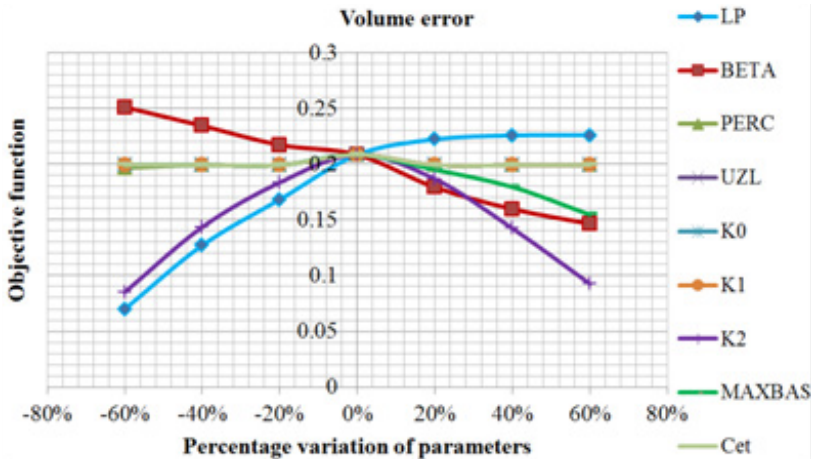

Figure 6 Sensitivity analysis by considering volume error.

Calibration and validation: Eight years (from January 1, 2002 to December 31, 2009) which includes one years of warm up, (from January 1, 2002 to December 31, 2003). And for the validation from January 2010-Dec 2012 the model performance of Geba watershed by HBV light model are satisfactory with objective functions like NSE and $\mathrm{R}^{2}$ greater than 0.60 and $\mathrm{Reff}=0.74, \mathrm{NSE}=0.72$ and $\mathrm{Reff}=0.73$, $\mathrm{NSE}=0.70$ for the calibration and validation period (Table 1).

Uncertainity analysis HBV light model: For this study Monte carlo simulation procedure was used to assess the uncertainity analysis in HBV light model.

a. 150000 model parameter run was produced

b. After selecting model run just select objective function Reff $>0.6$

c. Upper and lower bound was adopted

These results indicate a large equifinality of parameters and many unconstrained parameters. ${ }^{9}$ stated the concept of equinfinity concept in different cathment and he got large equinfinity and unconstrainted parameters. As it is shown in Figures 7-10 most part of the simulated hydrograph lays inside the uncertainty range or interval. In this study only parameter uncertainty is considered. Therefore the result of simulated flow is reliable. and researcher found that the simulation result lays outside the unceranity range as. ${ }^{8}$ stated clearly for uncertainty analysis in muger cathment abay basin, Ethiopia (Figures $11 \& 12$ ), (Table 2). ${ }^{10-12}$

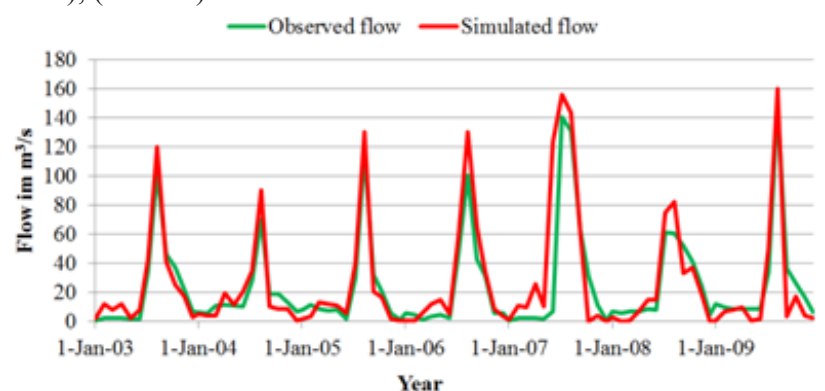

Figure 7 Observed and simulated flow hydrographs during calibration period.

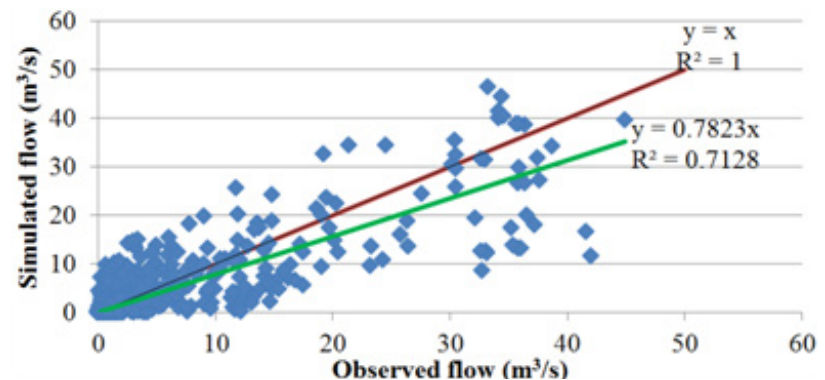

Figure 8 Scatter plot during calibration period in the Geba cathment.

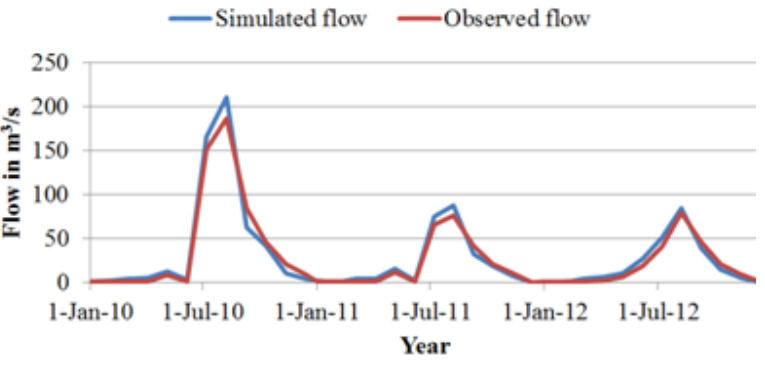

Figure 9 Observed and simulated hydrographs during validation period

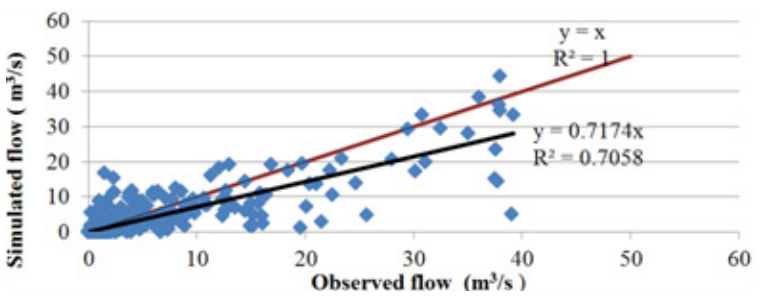

Figure 10 Scatter plot during validation period in the Geba cathment.
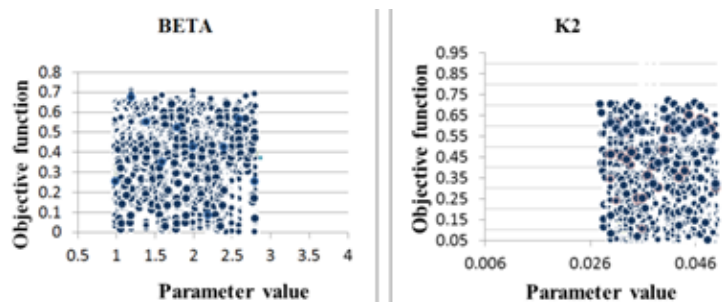

Figure I I Dotty plot for model parameters. 


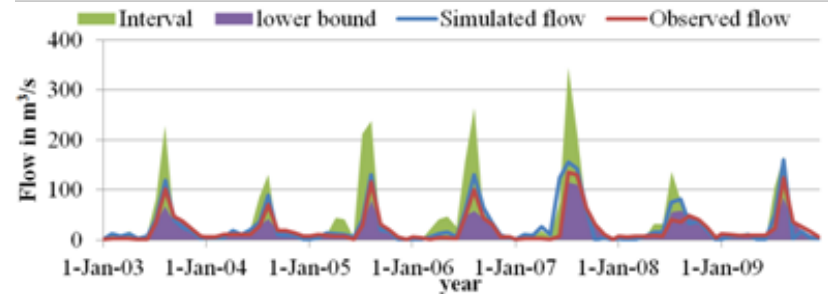

Figure 12 Uncertainity analysis in HBV light model.

Table I Model parameter values for HBV light

\begin{tabular}{|c|c|c|c|}
\hline Parameter & unit & $\begin{array}{l}\text { Valid } \\
\text { range }\end{array}$ & $\begin{array}{l}\text { Optimized parameter } \\
\text { value for calibration }\end{array}$ \\
\hline FC & $\mathrm{mm}$ & $(0$, inf $)$ & 850 \\
\hline LP & - & {$[0,1]$} & 0.8 \\
\hline BETA & - & $(0$, inf $)$ & 0.85 \\
\hline PERC & $\mathrm{mm} / \Delta \mathrm{t}$ & {$[0$, inf $)$} & 60 \\
\hline UZL & $\mathrm{mm}$ & {$[0$, inf $)$} & 50 \\
\hline $\mathrm{KO}$ & $\mathrm{I} / \Delta \mathrm{t}$ & {$[0,1)$} & 0.85 \\
\hline $\mathrm{KI}$ & $\mathrm{I} / \Delta \mathrm{t}$ & {$[0,1)$} & 0.55 \\
\hline $\mathrm{K} 2$ & $\mathrm{I} / \Delta \mathrm{t}$ & {$[0,1)$} & 0.65 \\
\hline MAXBAS & $\Delta \mathrm{t}$ & {$[1,100]$} & I \\
\hline Cet & $1 /{ }^{\circ} \mathrm{C}$ & {$[0,1]$} & 0.01 \\
\hline PCALT & $\% / 100 m$ & (-inf,inf) & 24 \\
\hline TCALT & ${ }^{\circ} \mathrm{C} / 100 \mathrm{~m}$ & (-inf,inf) & 0.9 \\
\hline Pelev & $\mathrm{m}$ & $(-$ inf,inf $)$ & 10.5 \\
\hline Telev & $\mathrm{m}$ & (-inf,inf) & 12.5 \\
\hline
\end{tabular}

Table 2 Performance of flow in calibration and validation period

\begin{tabular}{lllllll}
\hline $\begin{array}{l}\text { Simulation of } \\
\text { runoff }\end{array}$ & Reff & ENS & PBIAS & RSR & $\begin{array}{l}\text { Flow } \\
\text { weighted } \\
\text { efficiency }\end{array}$ & $\begin{array}{l}\text { Model } \\
\text { efficency/ } \\
\text { logreff }\end{array}$ \\
\hline $\begin{array}{l}\text { Calibration for } \\
\text { HBV light }\end{array}$ & 0.74 & 0.73 & - & - & 0.79 & $0.71 / 0.74$ \\
$\begin{array}{l}\text { Validation for } \\
\text { HBV light }\end{array}$ & 0.72 & 0.7 & - & - & 0.79 & $0.704 / 0.72$ \\
\hline
\end{tabular}

\section{Conclusions}

The following conclusions can be drawn from the foregoing discussions: The result from sensitivity analysis of

HBV light model soil routine parameter $\beta$ (shape coefficient), The recession curve, $\mathrm{K} 2$ and length of triangular weighted function (MAXBAS) were found to be the most sensitive parameters only in HBV light and due to this a major portion of the rainfall received Geba catchment quickly as direct runoff (surface dominance), This suggests different dominant runoff generation processes in the Geba cathment by the application of HBV light model. The majority of the ground surface of the study area covered with closely grown Agricultural land which its existence varying from season to season and with sparse vegetation. Most of the soil types available in the study area have clay soil texture which is known with its less permeability. These factors generate high runoff from the rainfall events, because unprotected land and less permeable soils are fast to get saturation level. The generation of high runoff depth results for high sediment generation and transport.

HBV light is good due to uncertainity analysis and parameters are identifiable and the dotty plot have less equinfinity or unconstrainied sample point.Form these regard futher water resource development and analysis selection of HBV light model is best due to best simulation of runoff for the cathment and for the future study of runoff simulation for the cathment proper data collection and analysis should be carried to minimize the uncertainity arises from different source. And from the dynamics for the model it have less performance in predicting low flow and extreme flood. More over, HBV light over estimate the low flow and the peak flow and poor model responses to high rainfall amount.

\section{Acknwoledgments}

None.

\section{Conflictfs of interest}

The author declare that there is no conflict of interest.

\section{Funding}

None.

\section{References}

1. Birhane. Estimation of monthly flow for ungauged catchment (Case Study Baro - Akobo basin) Ethiopia. MSc thesis. Addis Ababa University, Ethiopia. 2013;1-145.

2. Moreda. Conceptual Rainfall-Runoff Models for Different Time Steps with Special Consideration for Semi-arid and Arid Catchments. Laboratory of Hydrology and Inter-University Program in Water Resources Engineering. 1999.

3. IHMS. Integrated Hydrological Modeling System Manual. 2006.

4. Finicia et al. Understanding catchment behavior through stepwise model concept improvement. Water Resour Res. 2008;44(1):W01402.

5. Hundecha. Regionalization Parameters of Conceptual Rainfall-Runoff Model. University of Stuttgart Germany. 2005.

6. Gonfa. Climate classification of Ethiopia. Addis Ababa, Ethiopia. 1996.

7. Abraha. Assessment of spatial and temporal variability of river discharge, sediment yield and sediment-fixed nutrient export in Geba River catchment, northern Ethiopia. PhD thesis, Katholieke Universiteit Leuven, Belgium. 2009.

8. Kumela. Performance comparsion of rainfall runoff model on Muger cathment, abay basin. MSc. Thesis, addis ababa, Ehiopia. 2011.

9. Iuliia, Lutz Breuer, Irina Forkutsa, et al. Simulating Water Resource Availability under Data Scarcity —A Case Study for the Ferghana Valley (Central Asia). Water. 2014;6(11):3270-3299. 
10. Abbaspour. SWAT-CUP2: SWAT Calibration and Uncertainty Programs. In A User Manual. Department of System Analysis, Integrated Assessment and Modeling (SIAM), Eawag, Swiss Federal Institute of Aquatic Science and Technology. Duebendorf, Switzerland. 2009.

11. Gebre yohannes. Large-scale geological mapping of the Geba basin, northern Ethiopia [Tigray Livelihood Papers: 9]. VLIR -Mekelle University IUC Program. 2010;1-45.
12. Wagener, McIntyre, Lees MJ, et al. Towards reduced uncertainty in conceptual rainfall-runoff modeling: dynamic identifiability analysis. Hydrol Processes. 2003;17(2):455-476. 